\title{
The Impact of Comorbidities on COVID-19 Severity and Mortality in Egypt
}

Shereen Elghazaly ${ }^{1}$; Hanaa Abu El Sood ${ }^{1}$; Sahar Samy ${ }^{1}$; Mohamad AbdelFatah ${ }^{1}$; Mohamed Hassany ${ }^{1}$; Yousef Khader $^{2}$; Salma Afifi ${ }^{1}$; Alaa Eid $^{1}$

${ }^{1} \mathrm{MOHP}$, cairo, Egypt

${ }^{2}$ Jordan University of Science and Technology, Jordan, Jordan

\section{Corresponding Author:}

Shereen Elghazaly

Ministry of Health and Population

3 Magles Elshaab St

Cairo

Egypt

Phone: 201002925933

Email: drshereen84@yahoo.com

\section{Abstract}

Background: Older persons and people of any age with certain underlying comorbidities such as diabetes mellitus, cardiovascular disease, lung disease, kidney disease, liver disease, and cancer are at a higher risk of severe disease course and death if they become infected with COVID-19. Identifying at-risk groups and risk factors for COVID-19 severity and mortality is important for guiding the efficient and appropriate prevention and management of patients with COVID-19.

Objective: This study aimed at describing the demographics and epidemiologic characteristics of confirmed COVID-19 cases in Egypt and determining the impact of different comorbidities on patients' outcomes.

Methods: The data of all confirmed COVID-19 patients admitted to 408 governmental hospitals all over Egypt from February to May 2020 were collected retrospectively from the National Egyptian Disease Surveillance System. The cases were confirmed using RT-PCR.

Results: Overall, 28,415 patients (55\% male and $45 \%$ female) were identified. Their median age was 44 years. Of those, 743 (2.6\%) were admitted to ICU, $408(1.4 \%)$ required ventilator, and $1045(3.7 \%)$ died. Of the 21,617 (76.1\%) patients with completed data, 4687 (21.7\%) had comorbidities. Overall, 11.8\% had diabetes, 5.3\% cardiovascular disease, and 4.3\% chronic obstructive pulmonary disease. Those who had 1 comorbidity were more likely to die (odds ratio 2.83), were admitted to ICU (odds ratio 6.36), and needed a ventilator (odds ratio 5.95) compared to patients with no comorbidities. Having multiple comorbidities increased the risk of mortality (odds ratio 3.53), ICU admission (odds ratio 8.62), and requiring a ventilator (odds ratio 9.06).

Conclusions: COVID-19 patients with comorbidities had a higher risk of disease severity and mortality. Multiple comorbidities further increase the risk to a higher extent. All necessary precautions should be taken for patients with comorbidities to avoid COVID-19 infection in order to prevent the worst prognosis.

(iproc 2022;8(1):e36576) doi: $10.2196 / 36576$

\section{KEYWORDS}

COVID-19; comorbidities; mortality; severe outcome; public health surveillance. 
Edited by G Eysenbach; this is a non-peer-reviewed article. Submitted 18.01.22; accepted 19.01.22; published 07.02.22.

Please cite as:

Elghazaly S, Abu El Sood H, Samy S, AbdelFatah M, Hassany M, Khader Y, Afifi S, Eid A

The Impact of Comorbidities on COVID-19 Severity and Mortality in Egypt

iproc 2022;8(1):e36576

URL: https://www.iproc.org/2022/1/e36576

doi: $\underline{10.2196 / 36576}$

PMID:

(C) Shereen Elghazaly, Hanaa Abu El Sood, Sahar Samy, Mohamad AbdelFatah, Mohamed Hassany, Yousef Khader, Salma Afifi, Alaa Eid. Originally published in Iproceedings (https://www.iproc.org), 07.02.2022. This is an open-access article distributed under the terms of the Creative Commons Attribution License (https://creativecommons.org/licenses/by/4.0/), which permits unrestricted use, distribution, and reproduction in any medium, provided the original work, first published in Iproceedings, is properly cited. The complete bibliographic information, a link to the original publication on https://www.iproc.org/, as well as this copyright and license information must be included. 